\title{
EFFECTS OF IRRIGATION AND FERTIGATION ON YIELD AND QUALITY PARAMETERS OF 'GALA' AND 'FUJI' APPLE
}

\author{
Vladimír Mašán ${ }^{1}$, Patrik Burg ${ }^{1}$, Alice Čížková1, Jaromír Skoupil' \\ Pavel Zemánek ${ }^{1}$, Vladimir Višacki ${ }^{2}$
}

\begin{abstract}
${ }^{1}$ Department of Horticultural Machinery, Faculty of Horticulture, Mendel University in Brno, Zemedelska 1, 61300 Brno, Czech Republic

${ }^{2}$ Departman of Agricultural Engineering, Faculty of Agriculture, University of Novi Sad, Trg Dositeja Obradovića 8, 21000 Novi Sad, Serbia
\end{abstract}

To cite this article: MAŠÁN VLADIMÍR, BURG PATRIK, ČİŽKOVÁ ALICE, SKOUPIL JAROMÍR, ZEMÁNEK PAVEL, VIŠACKI VLADIMIR. 2018. Effects of Irrigation and Fertigation on Yield and Quality Parameters of 'Gala' and 'Fuji' Apple. Acta Universitatis Agriculturae et Silviculturae Mendelianae Brunensis, 66(5): 1183-1190.

To link to this article: https://doi.org/10.11118/actaun201866051183

\begin{abstract}
The climate change and growing production of crops increase the demand for the water and the efficient use of water in agriculture becomes more critical. This experiment presents the results of research in the orchard with different irrigation programs and fertigation on yield and quality parameters of the 'Gala' and 'Fuji' apple tree. Three irrigation programs were applied IR + F-full irrigation with fertigation; IR-full irrigation without fertigation; NON-IR - non-irrigation, only natural precipitations. There were no differences observed among these three irrigation programs for tree diameter, sugar content, starch content and fruits firmness $(P<0.05)$. Significant deficit of water was in program IR and NON-IR, at the length of annual growth, where the reduction was from from $680 \mathrm{~mm}$ to $440 \mathrm{~mm}$ at the 'GALA' variety. Statistically important differences between the irrigation variants were found out at the variety 'Fuji', in parametres yield, fruit weight and fruit diameter. Between programs IR + F and NON-IR was the difference of fruit weight $25.6 \mathrm{~g}(14.3 \%)$ and of fruit diameter $4.5 \mathrm{~mm}(5.8 \%)$.
\end{abstract}

Keywords: irrigation, fertilization, apple, 'Gala', 'Fuji'

\section{INTRODUCTION}

'Gala' and 'Fuji' are one of the most important apple cultivars highly demanded in the world apple industry. The apple cultivars in the 'Gala' group have a prominent place among the apple cultivars produced in the world. According to the estimations for 2020, it is envisaged that the place of 'Gala' in the ranking will remain unchanged (O'Rourke, 2016).

Since the effective root depths of new shapes of apple trees are short, the carrying out of such cultural practices, as irrigation and fertilization meticulously is quite important to increase the yield and water productivity (Ucar et al., 2016). Apple orchards need to be supplied with all macro- and micronutrients (Bennewitz et al., 2015; Bělíková et al., 2016).

The climate change and growing production of crops increase the demand for the water and the efficient use of water in agriculture becomes more and more critical (Fallahi et al., 2007).

Apple trees require irrigation to maintain high productivity and marketable fruit quality. Especially 
in high-density apple orchards, irrigation is important because tree roots strongly compete for the water and nutrients. Irrigation show a very positive influence of yield and quality of apples, especially during the dry years (Veverka and Pavlačka, 2012). In many fruit-growing regions, mineral nutrients are applied through irrigation system (fertigation), which gives possibility to control precisely both, water and nutrient (Wojcik and Treder, 2006).

The drip irrigation system covers the water needs of plants and assures a good water balance which is favourable for growth and development of the plants. Moreover, this method saves at least 39\% of water used compared to the full sprinkler system (Fallahi, 2017; Fallahi and Fallahi, 2017).

Merging new orchard designs with more efficient irrigation systems and nitrogen fertilization $(\mathrm{N})$ can result in lower water consumption while producing higher quality fruit (Fallahi et al., 2007; Neilsen et al., 2008).

Many other authors concluded that this resulted in major water saving and improved fruit and yield quality (in case it did not improve the quality, it lowered it only very little). Those plants that were not watered, had only small loss of water during the storage. Trees receiving the full irrigation systems had lower fruit firmness reduction after storage than the treatments receiving deficit irrigation systems (Fallahi and Fallahi, 2017; Yildirim et al., 2016; Naor et al., 2008).

Very similar are the results of the nitrogen fertilization. They show, that after two years the fruit in the low irrigation treatments were significantly smaller, but firmer, with higher total soluble solids (11.8 ${ }^{\circ} \mathrm{Bx}$ ) (Swarts et al., 2016).

On the other hand, for example Leib et al. (2006) indicated that fruit size and yield of 'Fuji' apple in deficit irrigation were similar to those of partial root zone drying irrigation and conventional irrigation in the semi-arid climate of Washington State.

This experiment presents the results of the research in the orchard of different irrigation and fertigation on yield and some quality parameters of the 'Gala' and 'Fuji' apple tree.

The aim of this experiment was to study the level of impact of different irrigation and fertilization with regards to the storage of nutrients and water in the soil during the past years.

\section{MATERIALS AND METHODS}

The experiment was conducted at the orchards of Plantex, Ltd. (Latitude: 48 $33^{\prime} 4.25^{\prime \prime} \mathrm{N}$, Longitude: $17^{\circ} 43^{\prime} 57.78^{\prime \prime} \mathrm{E}$ ) in the small town of Veselé, near city Pieštany, Slovakia, in the year 2017. The soils in the experimental area were classified as brown earth, medium-heavy type. The results from the agrotechnical experiments of soils are following: $\mathrm{pH} 7.2$ (neutral), content of phosphorus $142.0 \mathrm{mg} / \mathrm{kg}^{-1}$ (medium), potassium $441.0 \mathrm{mg} / \mathrm{kg}^{-1}$ (high), magnesium $391.0 \mathrm{mg} / \mathrm{kg}^{-1}$ (high), calcium $3737.0 \mathrm{mg} / \mathrm{kg}^{-1}$ (high). The climate of Slovakia (experimental area) can be classified as Cfb climate; a warm temperate humid climate. Annual precipitation varies from 550 up to $600 \mathrm{~mm}$. The average annual air temperature ranges from 9 to $10{ }^{\circ} \mathrm{C}$. The altitude of the experimental area is 161 meters above sea level. The 14-year-old 'Gala, Schniga' and 'Fuji, Kiku 8' apple trees grafted on M9 rootstock were used in the study. Trees were trained as spindle bush. The tree row was maintained by herbicides and the alleyways consisted of mown turf grass. The trees were planted with $3.6 \times 1 \mathrm{~m}$. Each row consisted of one variant with ten adjacent trees in the middle of the row.

\section{Irrigation and fertigation programs}

A year ahead of the experiment, irrigation and fertilization were carried out in a standard way, regular for the firm, so all the variants could unite. Irrigation water was obtained from the hydrant near to the experimental area. In the irrigation system, drippers, each with a discharge of $21 . h^{-1}$ and a space of $750 \mathrm{~mm}$, were placed one row above the trees on the construction.

Three irrigation programs were applied during the whole growth season: variant IR $+\mathrm{F}$ - full irrigation with fertigation; IR - full irrigation without fertigation; program NON-IR-non-irrigation, only natural precipitations. The overall irrigation dose is described in Tab. I. Information on irrigation were collected from the automatic irrigation system and information about precipitations from the meteostation of the firm. The fertilizers used were from the company 'Haifa Chemicals' (Israel), specifically: Ammonium sulfate, Chelated Iron $6 \%$ EDDHA, Humifirst, $\mathrm{KNO}_{3}$ Multi $\mathrm{K}, \mathrm{K}_{2} \mathrm{SO}_{4}$ Solupotasse, MKP. The irrigation and fertilization regime were operated by the automatic irritation system and adjusted accordingly to the respective employee. All trees in variant received the same amount of water.

\section{Vegetative growth, yield and fruit quality}

Tree diameter: measuring of the tree diameter was carried out before the beginning of the vegetation in the spring, and after the end of vegetation. The point of measurement was 0.8 meter above the soil surface.

Lengths of year growth: all one-year shoots from three trees per variants were measured after the end of vegetation period.

Yield and fruit quality: fruit of selected five trees from each variant were harvested, weighted, measured and analysed. The harvest date was determined on the basis of changes of fruit skin colour ('Gala', 28 August 2017) and starch degradation ('Fuji', 25 October 2017). Fruit of commercially important diameters, 55-90 mm were harvested.

Flesh firmness: this was set as an average of two opposite sides values measured by penetrometer mounted on a rigid, rigid drill stand with $11 \mathrm{~mm}$ tip after removing the peel. 
I: Values of the irrigation dose during the season

\begin{tabular}{lccccc}
\hline \multirow{2}{*}{ Month } & $\begin{array}{c}\text { A) full irrigation with } \\
\text { fertigation }(\mathbf{m m})\end{array}$ & $\begin{array}{c}\text { B) full irrigation without } \\
\text { fertigation }(\mathbf{m m})\end{array}$ & $\begin{array}{c}\text { C) non-irrigation, } \\
\text { only natural } \\
\text { precipitations (mm) }\end{array}$ \\
\cline { 2 - 5 } January & Gala & Fuji & Gala & Fuji & 14.6 \\
February & 0 & 0 & 0 & 0 & 32.0 \\
March & 0 & 0 & 0 & 0 & 28.8 \\
April & 0 & 0 & 0 & 0 & 45.2 \\
May & 165 & 129 & 154 & 118 & 26.5 \\
Jun & 115 & 118 & 115 & 118 & 50.7 \\
July & 148 & 137 & 137 & 120 & 52.5 \\
August & 232 & 241 & 193 & 204 & 102.7 \\
September & 230 & 216 & 190 & 188 & 74.4 \\
October & 28 & 28 & 28 & 28 & 29.2 \\
November & 0 & 0 & 0 & 0 & 53.6 \\
\hline All together & 0 & 0 & 0 & 0 & 510.2 \\
\hline
\end{tabular}

The sugar content: was measured on the laboratory optical ABBE refractometer $\left({ }^{\circ} \mathrm{Bx}\right)$.

The starch conversion code: was measured by the iodine test according to the colouring and further comparison with the appropriate table (CTIFL, 2002).

Fruit weight and diameter: all the harvested fruits from the trees were weigh by the electronic platform scale type CAS DB2 and then further averaged. The averages of the harvested fruits were measured in the plastic box.

\section{Statistical analysis}

The data were analysed together for both varieties. Two-factor ANOVA with interaction was used $(\mathrm{P}<0.05)$. Statistical analyses were performed by the software "Statistica 12.0" (StatSoft Inc., USA).

\section{RESULTS AND DISCUSSION}

\section{Tree diameter}

For the apple variety 'Gala', the largest trunk increments for vegetation were measured at variant NON-IR trees. Variant IR + F had smaller absolute increments. In variants of irrigation and between the measured varieties, there were no statistically significant differences (Fig. 1). Campi and García (2011) quoted the largest trunk increase at variant IR $+\mathrm{F}$, by $11 \%$, which is almost three times than our result. The reason for the difference can be a higher dose of nitrogen and different climatic and soil conditions. At variant NON-IR, the author gave the runk increment almost the same. In the 'Fuji' apple variety, the results were reversed.

\section{Length of annual growth}

Accordingly, to the expectations, significantly, the highest average annual length of the shoot had treatment with variant IR + F. Statistically insignificant was the difference between IR and NON-IR (Fig. 2).

\section{Sugar content}

In the 'Gala' variety, the highest average sugar content was at the variant NON-IR with $13.55^{\circ} \mathrm{Bx}$, followed by the variant IR $+\mathrm{F}$ with $12.8^{\circ} \mathrm{Bx}$ and

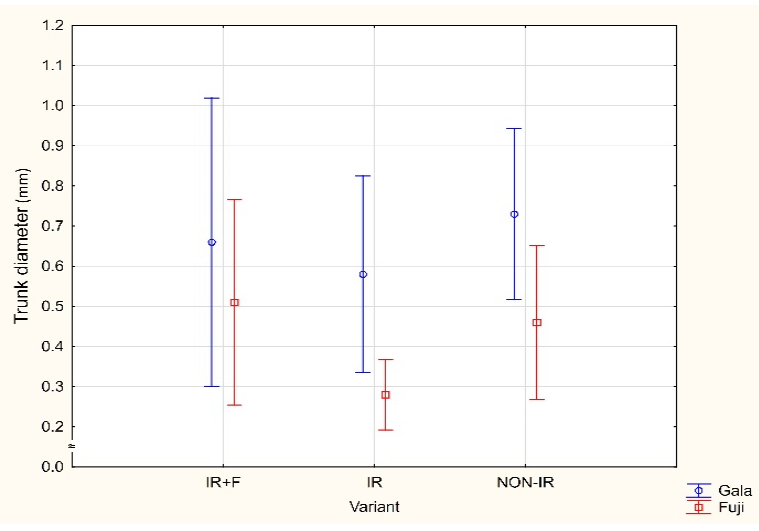

1: Trunk diameter increment per variety and variant 


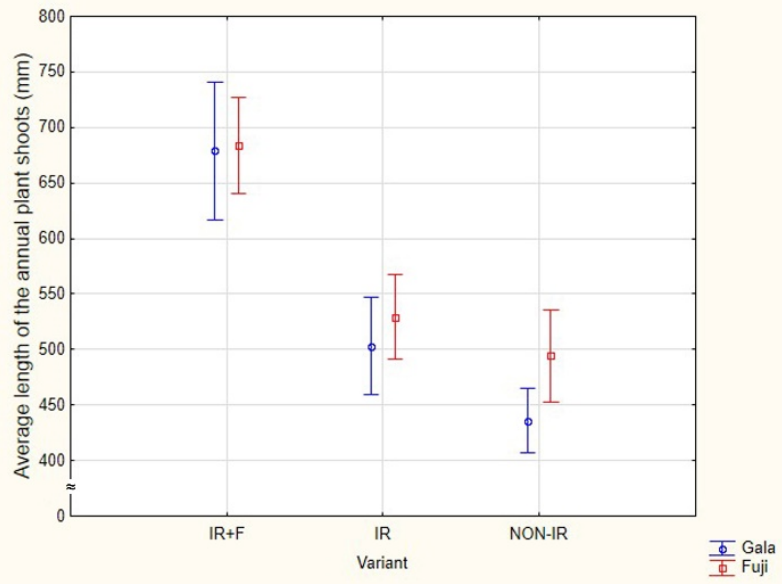

2: Average length of the annual plant shoots

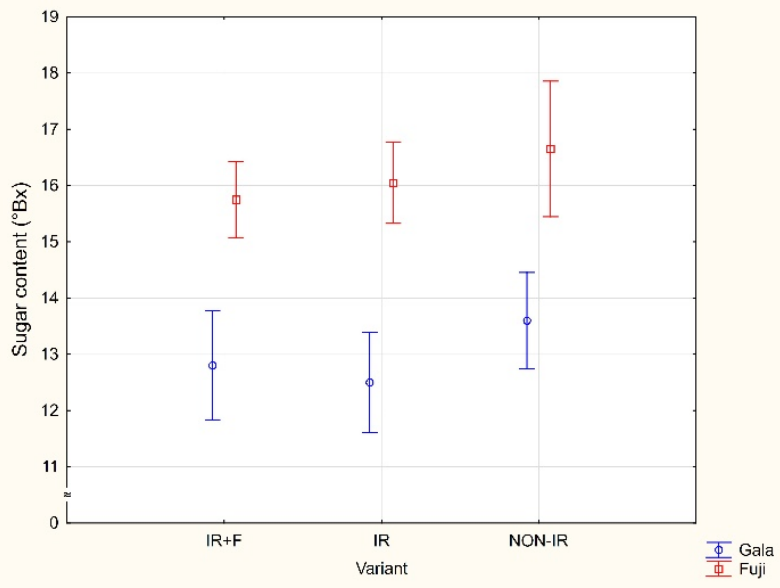

3: Sugar content per variety and variant

variant IR with $12.5^{\circ} \mathrm{Bx}$. The differences between variants were proven and the differences between the varieties are caused by the specific variety and the date of harvest (Fig. 3). Swarts et al. (2016) show a very similar sugar content as in our experiment. The higher sugar concentration in fruit variant NON-IR is, according to authors, caused by smaller fruits. In the 'Fuji' variety, the highest average sugar content was in variant NON-IR, $16.55^{\circ} \mathrm{Bx}$. Variant IR had an average sugar content of $16.05^{\circ} \mathrm{Bx}$ and variant IR $+\mathrm{F}$ of $15.75^{\circ} \mathrm{Bx}$. Fallahi (2017) reports sugar content around $16^{\circ} \mathrm{Bx}$ in their work. However, the order of the variants indicates the opposite, which justifies the climatic conditions of the given year. Wilcke (2005) reports optimum sugar content in fruit at harvest maturity of $12.5^{\circ} \mathrm{Bx}$ for the 'Gala' variety and $14^{\circ} \mathrm{Bx}$ for the 'Fuji' variety. This demand was achieved by both varieties and all three variants in the experiment.

\section{Starch conversion code}

The lower the starch value is, the more mature the apple and the higher the number of the degradation pattern is. Wilcke (2005) mentions an ideal starch degradation pattern ins between
5 to 7 for the 'Gala' variety and in between 4 to 6 for the 'Fuji' variety. In the 'Gala' variant IR + F, the average starch degradation pattern was 6.4, variant IR had an average starch degradation pattern 5.3 and variant NON-IR 4.3. This means, that the fruits in variant NON-IR were not yet mature. Similar results are reported by Swarts et al. (2016). The harvest of the 'Fuji' variety was done quite late for time reasons, but the difference across variants is still visible. The highest starch value contains variant NON-IR in the variety 'Fuji', which is same as in the 'Gala' variety. The highest starch degradation pattern of the average starch content had variant IR (9.7). Subsequently, variant IR + F had 9.5 and variant NON-IR 9.3. Wilcke (2005) states, that for the 'Fuji' variety, the most appropriate starch degradation pattern is between 4 and 6 . That means that in our case, the apples were harvested over ripped. Fallahi et al. (2018) state at the harvest maturity the starch degradation pattern is 4.0 in variant IR + F, 4.3 in variant NON-IR. This means that all variants were harvested mature. With the 'Gala' variety (Fig. 4), there is slight trend of differences between the varieties, but in general, these differences are statistically not important. 


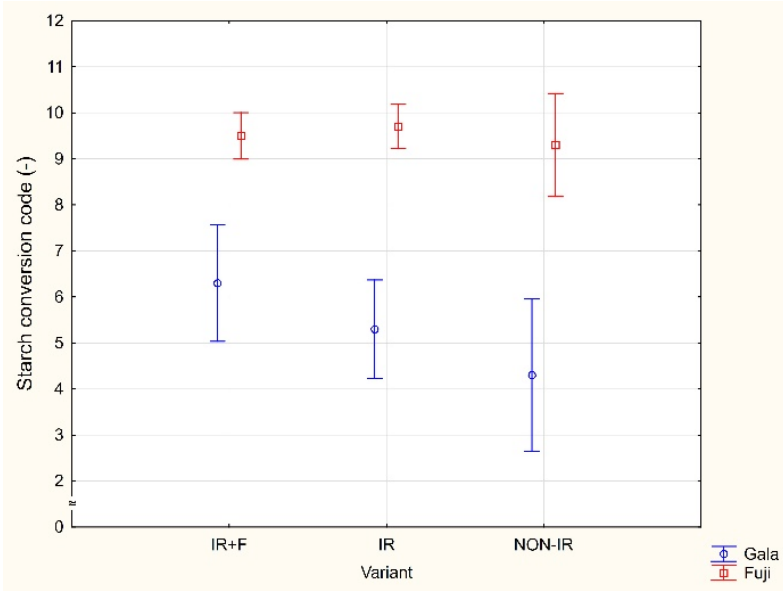

4: Starch conversion code pervariety and variant

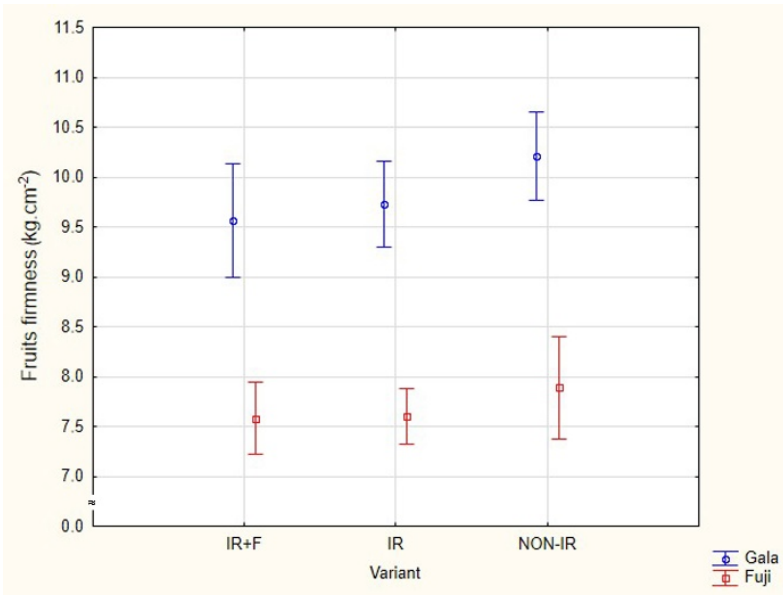

5: Fruits firmness pervariety and variant

\section{Fruits firmness}

For the firmness of the apples, the rule is simple-the softer, the more mature. Average firmness of the 'Gala' variety in variant IR + F was $9.56 \mathrm{~kg} . \mathrm{cm}^{-2}$, variant IR had an average firmness a bit higher $\left(9.73 \mathrm{~kg} . \mathrm{cm}^{-2}\right)$ and variant NON-IR had the highest firmness $10.21 \mathrm{~kg} . \mathrm{cm}^{-2}$. Wilcke (2005) gives the most appropriate firmness for harvest maturity at $8 \mathrm{~kg} \cdot \mathrm{cm}^{-2}$. Swarts et al. (2016) indicate firmness in variant IR $+\mathrm{F}$ the same as recommended by Wilcke (2005) for harvest maturity. Differences in firmness are due to the different climatic conditions. However, the differences between the variants are the same as in the experiment.

The average firmness of the 'Fuji' variety was the smallest at the variant IR $+F\left(7.58 \mathrm{~kg}^{-\mathrm{cm}^{-2}}\right)$, then variant IR $\left(7.6 \mathrm{~kg} . \mathrm{cm}^{-2}\right)$ and variant NON-IR (7.98 kg.cm-2). Wilcke (2005) reports an optimal firmness at harvest maturity of $6 \mathrm{~kg} . \mathrm{cm}^{-2}$, while Fallahi et al. (2010; 2018) reports a firmness of $7.3 \mathrm{~kg} . \mathrm{cm}^{-2}$ in variant IR + F. According to Yildirim et al. (2016), irrigation reduced the fruit flesh firmness, which confirms our results (Fig. 5). Similarly, to the results of Starch conversion code, these results are not proved by any statistic.

\section{Fruit weight}

In the 'Gala' variety, the average fruit weight was: in variant IR + F $146 \mathrm{~g}$, in variant IR $138 \mathrm{~g}$ and in variant NON-IR 132 g. Blažek (2001) and Campi and García (2011) report that the difference between non-irrigated and irrigated fruits with fertigation is between 15 and 30\%. However, the experiment shows a difference of only $10 \%$. According to Robinson (2006) the reason for this difference is the residual nutrient supply in the soil of the previous vegetation.

The average 'Fuji' fruit weight is one quarter higher than the 'Gala' variety. Variant IR $+F$ had an average fruit weight of $205.2 \mathrm{~g}$, variant NON-IR $183.2 \mathrm{~g}$, and variant IR $179.6 \mathrm{~g}$, event at this fruit variety, the difference of 15 and $30 \%$ was not confirmed between non-irrigated apples and apples irrigated with fertigation, as Blažek (2001) states. The measured difference was $11 \%$. Fallahi (2017) reports weight in variant IR + F $256 \mathrm{~g}$, which is almost $50 \mathrm{~g}$ more. The reason for this difference is apparently different cloud and clone. Statistically important difference was found out only at ther variant IR + F and only at the variety Fuji (Fig. 6). 


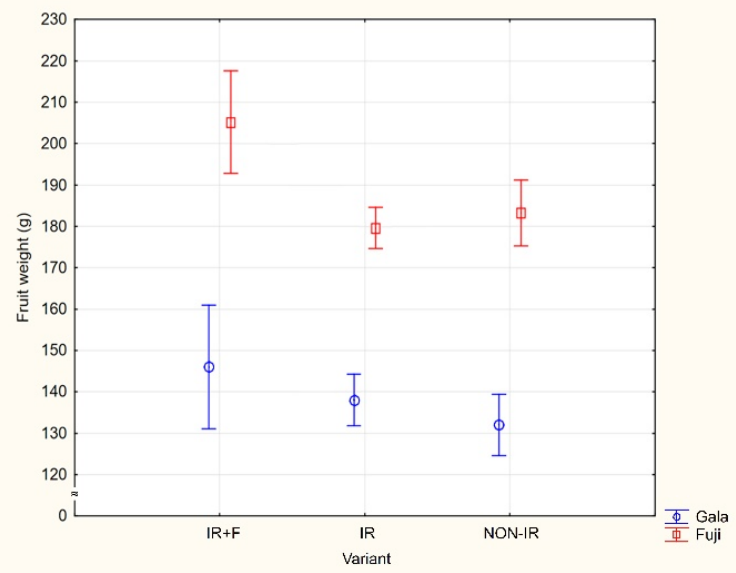

6: Fruit weight per variety and variant

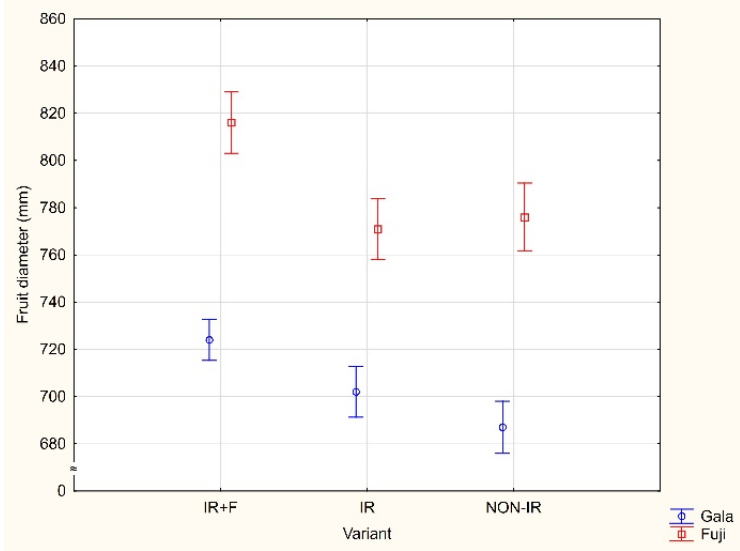

7: Fruit diameter pervariety and variant

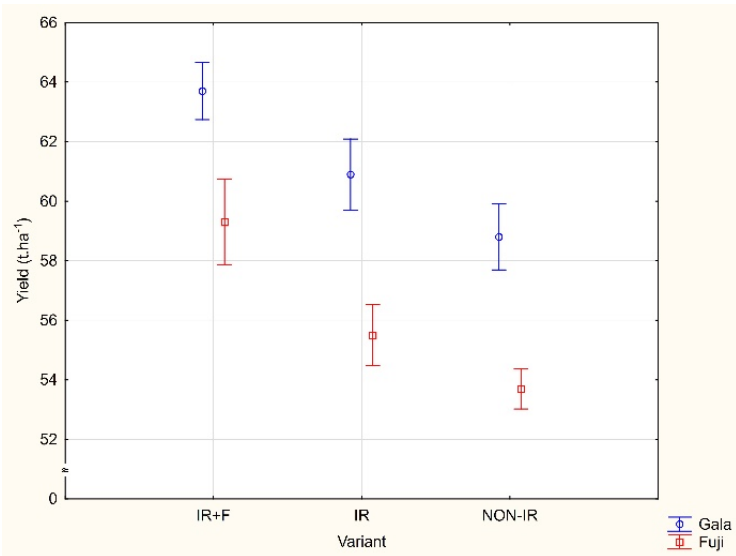

8: Effects of different irrigation treatments on yield

\section{Fruit diameter}

The fruit diameter of variety 'Gala' was in variant IR + F $72.4 \mathrm{~mm}$, in variant IR $70.2 \mathrm{~mm}$ and in variant NON-IR $68.7 \mathrm{~mm}$. Campi and García (2011) report almost the same diameter of the varieties in variant IR + F. In the variant NON-IR, they report smaller diameter of the apples - approximately $6 \mathrm{~mm}$ smaller. Yildirim et al. (2016) report, at the very similar climate conditions and as well after the first year of the experiment, almost the same diameters of the apples.

The fruit diameter of variety 'Fuji' was in variant $\mathrm{IR}+\mathrm{F} 81.6 \mathrm{~mm}$, and then in variant NON-IR $77.4 \mathrm{~mm}$. The smallest diameter was at the variant IR $77.1 \mathrm{~mm}$. The main reason for these results was probably not appropriate selection of the apples in May. Due to that, there are more apples on the tree, but with the shorter diameter as well as with 
the lower weigh. Fallahi and Fallahi (2017) report the biggest diameter of the fruits in variant IR $+\mathrm{F}$, which is $85.1 \mathrm{~mm}$, and the smallest diameter in variant NON-IR, which is $69.8 \mathrm{~mm}$.

The results of fruit diameter copy the results of fruit weight (Fig. 6 and 7). Moreover, statistically important difference was found out only at the variant IR + F and only at the variety 'Fuji'.

\section{Yield}

The total yield of the 'Gala' was 105\% higher in the IR + F and $103 \%$ higher in the IR variant than in the NON-IR. The total yield of the 'Fuji' was $105 \%$ higher in the IR + F and 104\% higher in the NON-IR variant than in the IR. Statistically important difference was found out at the variety 'Fuji' (Fig. 8).

Yildirim et al. (2016), Ucar et al. (2016) claim, that the total tree yield increased with irrigation level and are the same as authors Veverka and Pavlačka (2012) claim. The difference during the four years experiment between the variants $\mathrm{IR}+\mathrm{F}$ and NON-IR was at the level $50 \%$. On the other hand, Zegbe et al. (2007) claim, that the fruit yield at harvest was the same for the treatments.

\section{CONCLUSION}

The results obtained so far indicate the effect of the evaluated supplemental drip irrigation on the growth and the cavitative parameters of 'Gala' and 'Fuji' apple varieties. When evaluating the truncated strains where their diameter was determined, the values in all experimental variants were equalized without statistically significant differences. The annual plant shoots were the largest in full irrigation with fertigation variant in 'Fuji' variety and were $67 \mathrm{~mm}$, their lowest values were in non-irrigation variants, in the 'Gala' variety they were only $43 \mathrm{~mm}$. A significant qualitative indicator, when it comes to fruits, is the sugar content. The highest amount was determined for both varieties without irrigation, where the values varied between 13.5-16.5 Bx. For the market as well as for the farmers, the average weight of the fruit plays an important role. This was highest at the full irrigation with fertigation variant and was in 'Gala' variety $146 \mathrm{~g}$ and in 'Fuji' $205 \mathrm{~g}$. The weight of fruits is directly connected with their total yield, which was the highest at the full irrigation with fertigation. The total yield of the 'Gala' variety was 64 t.ha' ${ }^{-1}$ and of 'Fuji' 59 t.ha' .

\section{Acknowledgments}

The research was financially supported by the project CZ.02.1.01/0.0/0.0/16_017/0002334 'Research infrastructure for young scientists'.

\section{REFERENCES}

BĚLÍKOVÁ, H., ADAM, V., POKLUDA, R. and LOŠÁK, T. 2016. Effect of Foliar Application of Sulphur on Selected Parameters of Apple Fruits (Malus x Domestica Borkh) cv. Gloster. In: Proceedings from International Conference SOIL - the non-renewable environmental resource. Brno: Mendel University in Brno, pp. 35-42.

BENNEWITZ, Á., ALFREDO, E., COOPER, T. et al. 2015. Effect of decreasing levels of Namendments on organic "Granny Smith" apple trees. Journal of Soil Science and Plant Nutrition, 15(4): 79-90.

BLAŽEK, J. 2001. We grow apple trees [in Czech: Pěstujeme jablonẻ]. Praha: Brázda.

CAMPI, P. and GARCIA, C. 2011. Effects of irrigation management and nitrogen fertilization on the yield and quality of 'Gala' apple. Acta Hortic., 889: 249-255.

CTIFL. 2002. Starch apple code [in French: Code amidon pomme]. Paris: CTIFL.

FALLAHI, E., FALLAHI, B., SHAFII, B. et al. 2007. Water use, tree growth, and leaf mineral nutrients of young 'Fuji' apples as influenced by different irrigation systems. Acta Hortic., 721: 63-70.

FALLAHI, E., NEILSEN, D., NEILSEN, G. H. et al. 2010. Efficient Irrigation for Optimum Fruit Quality and Yield in Apples. Hort. Sci., 45: 1616-1625.

FALLAHI, E. 2017. Long-Term Influence of Irrigation Systems on Postharvest Fruit Quality Attributes in Mature ‘Autumn Rose Fuji' Apple Trees. International Journal of Fruit Science, 18(2): 177-187.

FALLAHI, E. and FALLAHI, B. 2017. Changes in water requirement, yield, and quality under various irrigation and nitrogen levels in 'Fuji' apples. Acta Hortic., 1177: 301-306.

FALLAHI, E., FALLAHI, B. and KIESTER, M. J. 2018. Evapotranspiration-based Irrigation Systems and Nitrogen Effects on Yield and Fruit Quality at Harvest in Fully Mature 'Fuji' Apple Trees over Four Years. HortScience, 53(1): 38-43.

LEIB, B. G., CASPARI, H. W., REDULLA, C. A. et al. 2006. Partial root zone drying and deficit irrigation of 'Fuji' apples in a semi-arid climate. Irrig. Sci., 25: 541-552.

NAOR, A., S. NASCHITZ, PERES, M. et al. 2008. Responses of apple fruit size to tree water status and crop load. Tree Physiology, 28(8): 1255-1261.

NEILSEN, D., NEILSEN, G. H., GREGORY, D. et. al. 2008. Drainage losses of water, N and P from microirrigation systems in a young, high density apple planting. Acta Hortic., 792: 48-490.

O'ROURKE, D. 2016. World apple review. Washington: Belrose, Inc. Available at: http://www.e-belrose.com/ [Accessed: 2018, February 7]. 
ROBINSON, T. L. 2006. Interaction of fertilization, rootstock and irrigation on growth, thinning efficiency, yield and fruit quality of 'Empire' apple. Acta Hortic., 721: 41-48.

SWARTS, N.D., HARDIE, M. and CLOSE, D. C. 2016. Precision nitrogenfertigation and irrigation management for improved apple quality. Acta Hortic., 1130: 485-490.

UCAR, Y., KADAYIFCI, A., AŞKIN, M. A. et al. 2016. Effects of Irrigation Frequency on Yield and Quality Parameters in Apple c.v. 'Gala, Galaxy'. Erwerbs-Obstbau, 58(3): 169-175.

VEVERKA, V., PAVLAČKA, R. 2012. The eff ect of drip irrigation on the yield and quality of apples. Acta univ. agric. et silvic. Mendel. Brun., 60(8): 247-25.

WOJCIK, P. and TREDER, W. 2006. Effect of drip boron fertigation on yield and fruit quality in a high-density apple orchard. Journal of plant nutrition, 29(12): 2199-2213.

WILCKE, C. 2005. Post-storage behavior of apple varieties as a function of storage duration and harvest date. [in German: Nachlagerverhalten von Apfelsorten in Abhängigkeit von Lagerdauer und Erntetermin]. Abschlussbericht F/E Projekt 2002 - 2004. Chemnitz: Sächsische Landesanstalt für Landwirtschaft.

YILDIRIM, F., VURAL, E., UÇAR, Y. et al. 2016. Interaction of Crop Load and Irrigation on Yield, Fruit Size, Color and Stem-end Splitting Ratio of Apple c.v. 'Gala, Galaxy'. Erwerbs-Obstbau, 58(2): 103-111.

ZEGBE,J.A.,BEHBOUDIAN,M.H.and CLOTHIER, B.E.2007.ReducedIrrigation Maintains Photosynthesis, Growth, Yield, and Fruit Quality in 'Pacific Rose ${ }^{\text {nu' }}$ Apple. Journal of Sustainable Agriculture, 30(2): 125-136.

Vladimír Mašán: vladimir.masan@mendelu.cz

Vladimír Višacki: vladimir.visacki@polj.uns.ac.rs 